\title{
Occupational Reintegration in Patients with Traumatic Brain Injury
}

\author{
Antonio Catano ${ }^{1 *}$, Paul Robert ${ }^{1}$, Myriam Houa ${ }^{1}$, Dan Hutanu ${ }^{1}$, Luc Bissen ${ }^{2}$ and Sabri El Banna ${ }^{3}$ \\ ${ }^{1}$ Department of Rehabilitation, CHU-Charleroi-Vésale, Belgium \\ ${ }^{2}$ Medical director, $\mathrm{CHU}$-Charleroi-Vésale, Belgium \\ ${ }^{3}$ Department of Orthopaedics \& Traumatology, CHU-Charleroi-Vésale, Belgium
}

\begin{abstract}
There is little information on the efficiencies and limits of the professional reintegration models among patients having suffered from a traumatic brain injury (TBI). In order to identify which factors should be taken into account to establish an accurate individual professional reintegration program, we have studied retrospectively the data from 56 consecutive patients having suffered a TBI with initial loss of consciousness. Our results indicate that many patients evidenced cognitive and executive functions disorders with negative impacts upon employment outcomes. In the patients who returned to work after the TBI, professional reintegration was achieved along with social integration process. Socioeconomic status also appears to affect the possibilities of work recovery as patients with lower levels of education and employment showed a poor outcome in returning to work. Among other positive features, young age at the time of the onset and facilities of arrangement of the work conditions tended to be useful for occupational reintegration and job recovery. However, our results have to be confirmed at a larger scale. Due to the low success of the professional reintegration process, we conclude that further research is needed to improve the management of patients after a TBI.
\end{abstract}

Keywords: Traumatic brain injury; Level of consciousness; Occupational reintegration process; Employment outcome; Social reintegration

\section{Introduction}

Traumatic brain injury [TBI] remains a leading cause of death and disabilities among young adults $[1,2]$. Incidence of TBI varies greatly between studies. As compared to $98 / 100,000$ in USA or to $160 / 100,000$ in India, it has been reported that the annual incidence of TBI was 235/100,000 in Europe with large disparities among countries:

$91 / 100,000$ in Italy, 435/100,000 in England or 546/100,000 in Sweden [3-5].

In Western countries, one person is victim of a TBI every three minutes, which represents 200,000 victims/year from which 50,000 will be hospitalized, 2,800 will die and 5,000 will keep permanent disabilities [6-8]. These figures do not include the 15,000 accidents of sport per year which are responsible for various behavioral disorders $[9,10]$.

In neuro-rehabilitation practice, diffuse cerebral lesions, either of hemorrhagic or of traumatic origin, are generally associated with a coma whose initial severity and duration will determine (a) the chances of survival and (b) the degree of the subsequent recovery [11-13]. In survivors, the impacts on the cerebral functioning are numerous and complex, affecting motor control, sensory modalities, psychointellectual function, language and writing, recognition of the familiar faces, perception of the environment, ... Unfortunately, patients will remain in a state of complete functional dependence for the Activities of Daily Life (ADL) in many cases.

Neurological rehabilitation aims primarily to promote the return to independence at home, in the society and at work. One of the fundamental missions of our Department of neuro-rehabilitation is to provide adequate neurological and/or cognitive rehabilitation treatments in order to to ensure an optimal integration with a priority for returning to work [14].

Our Department has 100 beds specifically intended for the neurological treatments of cerebral injuries. The daily care starts from the acute phase of the injury until the functional recovery and the return to autonomy. Continuation of the multidisciplinary treatments as ambulatory cares is provided when necessary. In addition, a special section is mainly dedicated to coma (whatever the origin), in particular during the phase of awakening. The multidisciplinary team is composed of medical specialists in physiatry, neurological, cardiac and pulmonary rehabilitation who are assisted by physiotherapists, psychologists, speech therapists, nurses, and social workers. They all work in conjunction to provide the best available care, taking into account the most recent scientific knowledge in this field.

The rate of unemployment is usually about $13 \%$ in professionally active people of our urban area which is of multi-ethnic and multicultural type [15]. As there is little information in the literature on the efficiency of the professional reintegration models for patients suffering from TBI, we strived for identifying which factors are needed to establish an accurate individual professional reintegration program.

\section{Materials and Methods}

We indexed the problems encountered in various fields (clinical, psychological, social, professional, administrative,...) during the process of professional integration among patients suffering from a TBI from January 2010 until December 2011.

\section{Patients}

56 consecutives patients were included in this retrospective study. They were all suffering from a TBI following motor vehicle accidents $(\mathrm{n}=31)$, falls or domestic accidents $(\mathrm{n}=8)$, work-related accidents $(\mathrm{n}=6)$, violence with physical abuse $(\mathrm{n}=6)$ and sport or recreational activities accidents $(n=5)$, resulting in a closed head injury with initial

*Corresponding author: Catano Antonio, Head of Department of Rehabilitation, University Hospital Centre of Charleroi - Vésale, 706 Rue de Gozée, B-6110 Montigny-le-Tilleul, Belgium, Tel:+3271923742; Fax +3271922951; E-mail: tony.catano@yahoo.co.uk, antonio.catano@chu-charleroi.be

Received November 19, 2014; Accepted February 26, 2015; Published March 04,2015

Citation: Catano A, Robert P, Houa M, Hutanu D, Bissen L, et al. (2015) Occupational Reintegration in Patients with Traumatic Brain Injury. Int J Neurorehabilitation 2: 150. doi:10.4172/2376-0281.1000150

Copyright: $\odot 2015$ Catano A, et al. This is an open-access article distributed under the terms of the Creative Commons Attribution License, which permits unrestricted use, distribution, and reproduction in any medium, provided the original author and source are credited. 
altered state of consciousness. The patients were hospitalized in our Department with the aims of a rehabilitation of the TBI. They were in the general market of labour at the time of the TBI. All the patients (or their relatives) gave their agreement for the present study, knowing that the results would not influence their medical and ancillary treatments. We excluded from the study the patients with a former disease interfering with the usual capacities of sustained work (neurological malformation, psychotic state, ...), those who were not in the market of labour at the time of the TBI, and those with standards of living interfering with the essential prerequisites of the market of labour (clan destinity, illegality, financial bankruptcy, social disintegration, ... ).

All the patients were addressed to our Department by the emergency department after stabilization of their vital functions or by the intensive care unit when their clinical state was compatible with rehabilitation. The primary neurological diagnosis on admission was cerebral concussion (6 men and 6 women), intra-ventricular haemorrhage (6 men and 4 women), subdural haematoma (10 men and 7 women) and diffuse axonal injury (10 men and 7 women). In line with the published recommendations, our 56 patients were divided into 3 groups according to the initial severity of the TBI as evaluated by (a) the Glasgow Coma Scale (GCS) (16) which grades a person's Level of Consciousness (LOC) on a numerical scale of 3 to 15 based on verbal, motor, and eye-opening reactions to stimuli, (b) the duration of Post-Traumatic Amnesia (PTA), and (c) the duration of the loss of initial conscience (LOC) [13,17-19]. Patients with "mild" TBI had an initial GCS score between 13 and 15, a duration of PTA lower than 24 hours and duration of initial LOC of less than 30 minutes. Patients with "moderate" TBI had initial values of GCS from 9 to 12, duration of PTA of less than 7 days and a LOC having lasted more than 30 minutes but less than 24 hours. The group with "severe" TBI had initial GCS values from 3 to 8 , duration of PTA of more than 7 days and LOC lasting more than 24 hours. Once in our Department, all the patients received a multidisciplinary rehabilitation consisting of daily physiotherapy, occupational therapy, speech and psychology therapies, according to the individual needs. The basic principles of rehabilitation and the procedures of hygiene, nutrition and medical supervision were adapted to each case according to the individual clinical state. The nursing care emphasized preventive interventions against pressure sores and eventual complications of prolonged immobilization. When present, the disorders of swallowing were treated accordingly by usual therapeutical measures or by parenteral nutrition.

The demographic, social, clinical and functional data were collected for all the patients of the 3 severity groups ("Mild", "Moderate" and "Severe") at days0 (D0, day of admission in our Department), 180 (D180) and 365 (D365).

\section{Patients' families}

The patients' families and relatives were regularly informed on the functional evolution and progress of the patient. They were asked to adopt a positive attitude. Counselling or psychological aid was provided when necessary.

During this study, the families and close relations were informed that they could visit the patient by their own way (providing the respect of the usual constraints of the medical therapeutics) and that they could accompany them in the eventual administrative procedures without any restriction.

\section{Socio-professional status evaluation}

The socio-professional status was recorded on admission in our department (D0), then at D180 and at D365 according to structured and directed questioning about the educational, financial, marital, familial and professional aspects.

The educational background was estimated by considering the educational level with the highest diploma obtained by the person in primary education, secondary and higher education degrees. As a majority of surveyed people do not declare reliably their annual income, and their financial status was evaluated by investigating the standards of living of the households. The familial and marital status was investigated in order to determine whether a person was socially isolated.

The professional status was estimated following the French nomenclature of the professions and socio-professional categories which contains 6 professional groups [20]. Within these 6 professional groups, the unemployed persons who had already occupied an employment were classified among the categories of professionally active ones according to their last profession.

Patients ensuring a professional training or working on a parttime or full time basis were considered as having a paid job. In patients who had no paid job at D180 and D365, the causes of unemployment were collected and classified into medical reasons, lack of motivation, inability to cope with prior job, unavailability of job arrangement and inability to cope with administrative procedures.

\section{Clinical status evaluation}

The clinical status was recorded at day 0 (D0, date of admission in our department), D180 and D365 by using a structured interrogation procedure followed by a clinical examination including the somatic, neurological, functional and neuropsychological evaluations.

The functional evaluations were performed using the Barthel Index (BI; 21) which measures the functional consequences of the patient's incapacities and their temporal evolution $[22,23]$.

The neuropsychological testing consisted of the evaluation of the cognitive and linguistic functions, the capacities of attention and orientation (including the memory and attention areas) as well as tests assessing executive functioning; these tests were possibly supplemented by the evaluation of apraxia, agnosia, calculation, writing, and reasoning. All the neuropsychological tests were calibrated according to age, gender and socio-cultural level.

\section{Statistical analysis}

Statistical analysis was carried out by using the "Statistical Social Package for the Sciences" (SPSS, version 16). We first assessed the normality of data before performing nonparametric statistical tests; all the tests were bilateral. The results are listed with mean values \pm Standard Deviations (SD). When indicated, we used contingency tables with Chi-square or Fisher's Exact Test with two-sided P values.

\section{Results}

The main demographic and socio-professional data of all the patients included in this study $(\mathrm{n}=56)$ are summarized in Table 1 .

\section{Demographic data}

The 56 patients with TBI were 32 men and 24 women with respective mean ages of $39 \pm 11$ and $33 \pm 13$ years. There was no statistical difference between the 2 groups in comparison with the $36 \pm$ 12 years of the initial cohort (Student $t$ test; $\mathrm{P}=0.28$ ). According to the initial severity of the TBI, the 56 patients were divided into 3 severity groups ("Mild", "Moderate" and "Severe" TBI). Within each of the 3 
Citation: Catano A, Robert P, Houa M, Hutanu D, Bissen L, et al. (2015) Occupational Reintegration in Patients with Traumatic Brain Injury. Int J Neurorehabilitation 2: 150. doi:10.4172/2376-0281.1000150

Page 4 of 8

\begin{tabular}{|c|c|c|c|c|}
\hline Severity group & Mild & Moderate & Severe & $P$ values \\
\hline Men/women & $4 / 4$ & $12 / 9$ & $16 / 11$ & NS a \\
\hline Age (year) & $38 \pm 11$ & $37 \pm 12$ & $35 \pm 13$ & NS a \\
\hline Mortality at : D180 & 1 & 5 & 9 & NS ${ }^{b}$ \\
\hline D365 & 0 & 0 & 4 & NS ${ }^{b}$ \\
\hline \multicolumn{5}{|l|}{ Level of education $(n=56)$} \\
\hline None $(n=5)$ : & 0 & 1 & 4 & NS ${ }^{\text {a }}$ \\
\hline Primary $(n=19)$ : & 2 & 7 & 10 & NS a \\
\hline Secondary $(n=26)$ : & 4 & 10 & 12 & NS ${ }^{a}$ \\
\hline Higher $(n=6)$ : & 2 & 3 & 1 & NS a \\
\hline Family status at D0 $(n=56)$ : Isolated & 1 & 2 & 3 & \\
\hline Non- isolated & 7 & 19 & 24 & NS ${ }^{b}$ \\
\hline D180 $(n=41):$ Isolated & 1 & 2 & 2 & \\
\hline Non- isolated & 6 & 14 & 16 & NS ${ }^{b}$ \\
\hline D365 $(n=37)$ : Isolated & 1 & 2 & 2 & \\
\hline Non- isolated & 6 & 14 & 12 & NS ${ }^{b}$ \\
\hline $\mathrm{Nr}$ of patients with job at D0 $(n=56):$ Job & 7 & 18 & 21 & \\
\hline Unemployed & 1 & 3 & 6 & NS ${ }^{b}$ \\
\hline $\mathrm{D} 180(\mathrm{n}=41): \mathrm{Job}$ & 7 & $7 *$ & $1 * *$ & \\
\hline Unemployed & 0 & 9 & 17 & NS ${ }^{b}$ \\
\hline D365 $(n=37):$ Job & 7 & 11 & $2 * * *$ & \\
\hline Unemployed & 0 & 5 & 12 & NS ${ }^{b}$ \\
\hline
\end{tabular}

$\mathrm{a}=$ KRUSKAL-WALLIS Statistic; ${ }^{\mathrm{b}}=$ Fisher's Exact Test, NS = non-significant

* $\mathrm{P}=0.0124$ when compared to D0 (Fisher's Exact Test)

** $\mathrm{P}<0.0001$ when compared to D0 (Fisher's Exact Test)

*** $P=0.0002$ when compared to D0 (Fisher's Exact Test)

Table 1: demographic and social data (mean values \pm SD) in our patients.

severity groups, the mean ages did not significantly differ according to the gender (Kruskal-Wallis Statistic; $\mathrm{P}=0.61$ ).

\section{Mortality}

The overall mortality rate at D365 was $34 \%$ (19 patients, 12 men and 7 women). $27 \%$ of patients ( $\mathrm{n}=15,10$ men and 5 women) died before D180. Statistical analysis revealed that there was no significant difference in mortality according to gender or between each severity group at D180 and at D365 (Fisher's Exact Test ; P = 0.6) (Table 1).

\section{Socio-professional status}

The educational background was evaluated on admission. The social status evaluation on admission is listed in Table 1. Analysis indicated that for eachseverity group, the mean number of patients in each education category did not significantly differ according to the gender (Chi-squared Test; $\mathrm{P}=0.75$ ). Within each severity groups, there was no significant difference in the education status according to the gender (Chi-squared Test; $\mathrm{P}=0.95$ ). Statistical analysis indicated no significant difference between categories within each severity group accordingly at D180 and D365 (Kruskal-Wallis; $\mathrm{P}=0.31$ ).

There was no significant difference in the patients' financial status as evaluated with the standards of living of the households within each severity groups, according to gender or between them respectively (Chisquared Test; $\mathrm{P}=0.64$ ). The evaluation of the social status (determining if a patient was socially isolated) indicated no statistical difference for gender at D0 (Fisher's Exact Test; $\mathrm{P}=0.69$ ) in severity groups. Statistical analysis indicated no significant difference between categories in each group accordingly at D180 (Fisher's Exact Test; P = 1.0) and D365 (Fisher's Exact Test; $\mathrm{P}=1.0$ ) (Table 1).

The professional status (determining if a patient had a paid job at the time of the TBI) indicated no statistical difference for gender (Fisher's
Exact Test; $\mathrm{P}=0.85)$ at $\mathrm{D} 0$. Analysis indicated no significant difference between survivors in each group accordingly at D180 (Fisher's Exact Test; $\mathrm{P}=0.29$ ) and D365 (Fisher's Exact Test; $\mathrm{P}=0.57$ ).

Statistical analysis (Fisher's Exact Test) indicated that within the "Mild" severity group there was no significant difference between categories at D0, D180 and D365 (P = 1.0) (Table 1). Within the "Moderate" group, there was a significant association between the initial severity of the TBI and the level of employment at D180 ( $\mathrm{P}=0.0124$, Fisher's Exact Test). For the "Severe" group, there was a significant association between the initial severity of the TBI and the level of employment at D180 ( $\mathrm{P}<0.0001)$ and D365 $(\mathrm{P}=0.0002$; Fisher's Exact Test).

After pooling the data of employment outcomes in the 56 patients at D0, in the 41 survivors at D180 and in the 37 survivors at D365, statistical analysis (Fisher's Exact Test) revealed a significant difference in the professional status at $\mathrm{D} 180(\mathrm{P}<0.0001)$ and at $\mathrm{D} 365(\mathrm{P}=0.0002)$ while there was no statistical difference between D180 and D365.

On admission, the mean age (years) of the patients who had a job at the time of the brain injury $(n=46)$ was $36 \pm 12$ years. The mean age was $36 \pm 12$ years in patients who were unemployed $(n=10)$. At D180, the mean age was $28 \pm 9$ years in patients who had recovered a job and $35 \pm 10$ years in the unemployed patients. At D365, the mean age was 27 \pm 7 years in patients who had recovered a job and $39 \pm 11$ years in the patients who did not. By comparison with the mean age of patients who were unemployed on admission (Mann-Whitney U-Statistic), the mean age of patients who regained a job was significantly smaller at D180 $(\mathrm{P}=$ $0.0101)$ and at $\mathrm{D} 365(\mathrm{P}=0.0008)$.

Among the 5 patients who had no diploma or specialized qualification at D0 (one patient with "Moderate" TBI and 4 patients with "Severe" TBI), none of them was found to have recovered a job or 
to follow a professional training at D180 or D365. From the 6 patients (4 men and 2 women) who were socially isolated on admission, one (female) patient from the "Moderate" group wasworking on a part-

\begin{tabular}{|c|c|c|c|c|}
\hline Severity group & Mild & Moderate & Severe & $P$ values \\
\hline D180 (Men/women) & $0 / 0$ & $5 / 4$ & $9 / 8$ & NS a b \\
\hline Medical disorders : & 0 & 2 & 11 & NS ${ }^{b}$ \\
\hline Lack of motivation : & 0 & 1 & 0 & NS ${ }^{b}$ \\
\hline Inability to cope with job: & 0 & 0 & 5 & NS ${ }^{b}$ \\
\hline No job arrangements : & 0 & 2 & 0 & NS ${ }^{b}$ \\
\hline Diff. with administrative proc. : & 0 & 4 & 1 & NS ${ }^{b}$ \\
\hline Total $(n=26)$ : & 0 & 9 & 17 & NS ${ }^{b}$ \\
\hline D365 (Men/women) & $0 / 0$ & $3 / 2$ & $6 / 6$ & NS ${ }^{a b}$ \\
\hline Medical disorders : & 0 & 1 & 9 & NS ${ }^{b}$ \\
\hline Lack of motivation : & 0 & 0 & 0 & NS ${ }^{b}$ \\
\hline Inability to cope with job: & 0 & 1 & 0 & NS ${ }^{b}$ \\
\hline No job arrangements : & 0 & 2 & 0 & NS ${ }^{b}$ \\
\hline Diff. with administrative proc. : & 0 & 1 & 3 & NS ${ }^{b}$ \\
\hline Total $(n=17)$ : & 0 & 5 & 12 & NS ${ }^{b}$ \\
\hline
\end{tabular}

NS = non-significant

a = comparisons between "Moderate" and "Severe" groups (Fisher's Exact Test) $\mathrm{b}=$ comparisons between homologous values at D180 and D365 (Fisher's Exact Test)

Table 2: Causes of unemployment in jobless patients at D180 and D365.

\begin{tabular}{|l|c|c|}
\hline Symptoms & D180 $(\mathrm{n}=41)$ & $\mathrm{D} 365(\mathrm{n}=37)$ \\
\hline Anxiety & 33 & 29 \\
\hline Asthenia & 30 & 25 \\
\hline Headache & 30 & 26 \\
\hline Sleep disorder & 28 & 22 \\
\hline Dizziness & 27 & 8 \\
\hline Depressive state & 21 & 18 \\
\hline Reduced libido & 18 & 16 \\
\hline Disorders of vision & 12 & 0 \\
\hline Psychomotor agitation & 12 & 0 \\
\hline Character disorder & 9 & 9 \\
\hline Tinnitus (whistling/ buzzing) & 6 & 2 \\
\hline
\end{tabular}

Table 3: Disorders referred by the patients.

time basis at D180 and at D365 while one (male) patient from the same severity group was following a professional training at D365.Among the 4 patients who were both socially isolated and jobless at D0 (2 men and 2 women, equally distributed into both "Moderate" and "Severe" groups), none of them had regained a job or followed a professional training at D180 or D365. The causes of unemployment were collected in the patients who had not recovered their job at D180 $(n=26,14$ men and 12 women) and D365 ( $\mathrm{n}=17,9$ men and 8 women). The causes of unemployment at D180 and D365 are listed in Table 2. Statistical analysis showed no significant difference between the 2 severity groups for each category of cause of unemployment according to the gender at D180 and D365 (Fisher's Exact Test; $\mathrm{P}=1.0$ respectively) (Table 2).

\section{Clinical evaluation}

Besides the classical clinical and functional examinations, the specialized and clinical evaluations at D0, D180 and D365 indicated persistent neurological complications such as post-traumatic hydrocephaly $(n=5)$, epilepsy $(n=10)$, frontal lobe syndrome $(n=6)$, chronic vegetative state $(n=3)$ and minimally conscious state $(n=5)$. Seven patients had post-traumatic epilepsy. All the patients eligible for neuropsychological evaluation at D180 $(n=33)$ and D365 $(n=29)$ had evidence of disorders of attention, memory and executive functions.

\section{Clinical status evolution}

Furthermore, many patients presented mood disorders along with character and personality changes. The frequencies of the neuropsychiatric anomalies at D180 and D365 are presented in Table 3.

The main complaints referred spontaneously by the patients at D180 and D365 were anxious disorders, asthenia and headache. At D180, 21 patients suffered from a depressive state and at D365, they were still 18 patients to be treated for depression. Some anxious manifestations such as sleep disorder, dizziness, disorder of vision, psychomotor agitation, and tinnitus tended to lessen over time while character disorder did not.

\section{Functional status evolution}

The functional status (evaluating the functional consequences of the patient's incapacities) was measured at D0, D180 and D365 in all patients by using the BI. Table 4 summarizes the mean BI values within

\begin{tabular}{|c|c|c|c|c|}
\hline $\begin{array}{l}\text { Severity group } \\
\mathrm{BI}\end{array}$ & Mild & Moderate & Severe & $P$ values \\
\hline $\begin{array}{l}\text { D0 } \\
\text { Men }(n=32): \text { Women }(n=24) \text { : } \\
\text { All }(n=56):\end{array}$ & $\begin{array}{l}89 \pm 5(n=4) \\
86 \pm 3(n=4) \\
88 \pm 4(n=8)\end{array}$ & $\begin{array}{c}73 \pm 27(n=12) \\
85 \pm 7(n=9) \\
78 \pm 5(n=21)\end{array}$ & $\begin{array}{c}35 \pm 24^{a} \\
(n=16) \\
40 \pm 23^{b} \\
(n=11) \\
38 \pm 23^{*} \\
(n=27)\end{array}$ & $\begin{array}{l}N^{a}{ }^{a} \\
N S^{a}\end{array}$ \\
\hline $\begin{array}{l}\text { D180 } \\
\text { Men }(n=22): \text { Women }(n=19): \\
\text { All }(n=41):\end{array}$ & $\begin{array}{l}100 \pm 0(n=4) \\
100 \pm 0(n=3) \\
100 \pm 0(n=7)\end{array}$ & $\begin{array}{c}88 \pm 31(n=9) \\
97 \pm 4(n=7) \\
92 \pm 23(n=16)\end{array}$ & $\begin{array}{c}37 \pm 42(n=9) \\
53 \pm 30(n=9) \\
45 \pm 36^{*} \\
(n=18)\end{array}$ & $\begin{array}{l}N^{c}{ }^{c} \\
N S^{c}\end{array}$ \\
\hline $\begin{array}{l}\text { D365 } \\
\text { Men }(n=20): \text { Women }(n=17): \\
\text { All }(n=37):\end{array}$ & $\begin{array}{l}100 \pm 0(n=4) \\
100 \pm 0(n=3) \\
100 \pm 0(n=7)\end{array}$ & $\begin{array}{c}88 \pm 31(n=9) \\
98 \pm 3(n=7) \\
93 \pm 23(n=16)\end{array}$ & $\begin{array}{c}47 \pm 44(n=7) \\
64 \pm 26(n=7) \\
55 \pm 36^{* *} \\
(n=14)\end{array}$ & $\begin{array}{l}N^{c}{ }^{c} \\
N S^{c}\end{array}$ \\
\hline
\end{tabular}

a : $\mathrm{P}=0.0008$ when compared to Moderate group and $\mathrm{P}=0.0004$ when compared to Mild group (MANN-WHITNEY U-statistic)

$\mathrm{b}: \mathrm{P}<0.0001$ when compared to Moderate group and $\mathrm{P}=0.0015$ when compared to Mild group (MANN-WHITNEY U-statistic)

c: KRUSKAL - WALLIS statistic

$\mathrm{NS}=$ non significant

* $\mathrm{P}<0.001$ when compared to Mild and Moderate groups (DUNN's Multiple Comparisons Test)

*** $\mathrm{P}<0.01$ when compared to Mild and Moderate groups (DUNN's Multiple Comparisons Test)

Table 4: mean BARTHEL Index values within the 3 severity groups by gender over time (mean values \pm SD). 
the 3 severity groups by gender over time. On admission, at D180 and at D365, there were significant differences for the mean BI in the "Severe" TBI group as compared to the "Moderate" or "Mild" groups (MannWhitney U-Statistic, Dunn’s Multiple Comparisons Test).

When comparing the mean BI of all patients by gender over time, statistical analysis indicated a significant difference between the mean BARTHEL Index at D180 with P $=0.0137$ in men and $\mathrm{P}=0.0449$ in women (Mann- Whitney U-Statistic) while there was no statistical difference at D365 in comparison with D180 (Mann-Whitney Test ; P $=0.49$ ).

Analysis of the data of all the patients showed a statistical difference between the mean BARTHEL Index at D180 $(\mathrm{P}=0.0011$; Mann-Whitney U- Statistic) and at D365 (P <0.0001; Mann-Whitney U-Statistic) while there was no statistical difference between D180 and D365 (Kruskaul-Wallis Statistic; P =0.94)

\section{Discussion}

In our study, the 56 patients were in the general market of labour at the time of their TBI. We grouped them according to the initial severity of the brain injury. Their demographic data and their socio-professional status on admission showed no statistical difference. Although the sample of our study is very small, our results indicate globally that mean functional recovery was significantly improved from D180 on, as was the mean job recovery rate that was statistically different either when gathering the data from the whole cohort or when pooling them according to the gender or to the initial degree of severity of the TBI (Table1). This suggests that in our series the job recovery rate could eventually be associated mainly with the degree of functional recovery at D180 although improvement of neurological function can occur for two or more years after the initial trauma[13].

Administrative procedures are a complex matter that commonly requires intact executive functions and cognitive skills in healthy people. $48 \%$ had presented a severe initial coma and there were 14 cases out of $56(25 \%)$ with known poor outcome as 6 patients had a "frontal lobe syndrome", 3 patients had a"chronic vegetative state" and 5 patients suffered from a minimally conscious state [17,24-28]. All the patients evidenced neuropsychological disorders of attention, memory and executive functions with possible negative impact upon work performances at D180 and D365 [2,29,30]. Furthermore, at D180, 21patients (51\%) suffered from a depressive state and 9 from a character disorder (22\%) which did not improve significantly overtime. The frequencies of the neuropsychiatric disorders collected at D180 and D365 (Table2) suggest actual difficulties in coping with occupational activities and/or with main administrative procedures in order to keep, regain or find a job. Similar results have already been reported [31]; in a series of 846 patients with severe TBI less than one- third of cases had a good recovery (defined as mild or no disability) and able to return to work or school [32]. When considering the rates of unemployment overtime in our series, we noticed that, on admission, 10 out 56 patients were already unemployed (18\%). This rate of unemployment is slightly above the expectation in our area (13\%). This could result from our procedures of recruitment since we had a predominance of $48 \%$ of patients in the group with "Severe" TBI on admission. At D180, 16 patients out of $41(39 \%)$ were unemployed. At D365, they were 17 out of $37(46 \%)$. However, statistical analysis showed no significant difference between these figures.

Compared to the unemployed patients, the mean age of patients who recovered a job was significantly lower at $\mathrm{D} 180(\mathrm{P}=0.0101)$ and at D365 ( $\mathrm{P}=0.0008)$ (Mann-WhitneyU-Statistic). An eventual effect of mortality upon the employment out comes can be discarded as there was no statistical difference in mortality from D180 until D365 (Table1). Generally, younger adult patients with TBI have better recovery than older ones. This is in agreement with the literature; this parameter is a powerful independent prognostic variable of positive outcome after a TBI [13], the odds for a poor outcome being increased by 40 to $50 \%$ per 10 years of age [33]. Younger patients with better recovery could develop earlier compensatory strategies and work with employers to arrange appropriate accommodations.

Similar consideration can be made for the financial status aspects as analysis showed no statistical difference between the 3 severity groups. Actually, our recruitment procedures had discarded patients with standards of living interfering with the prerequisites of the market of labour. Low financial income tends to worsen clinical outcomes in patients with TBI $[34,35]$. Nevertheless, all our patients had equal access to medical care facilities and could benefit from national insurance resources. Among the 5 patients who had no diploma or specialized qualification at D0 (one patient with "Moderate" TBI and 4 patients with "Severe" TBI), none of them was found to have gained a job or to follow a professional training at D180 or D365. Severity of the initial injury to the brain and poor level of education have shown lower functional outcome $[6,13,36-38]$ which could result in lesser employment rates. From our 6 patients ( 4 men and 2 women) who were socially isolated on admission, only 2 were working or following a professional training at D365 and among the 4 patients who were both socially isolated and jobless at D0, none of them had found a job or was engaged in a professional training at $\mathrm{D} 365$. Social isolation has proved to be a negative factor on employment outcomes after a TBI [39-41]. Using the Craig Handicap Assessment and Reporting Technique(CHART), O'Neill etal. (1998) identified a significant positive correlation between employment and social integration for individuals with TBI that had returned to full or part-time work. Indeed, even in otherwise healthy individuals social isolation may result in psychological and physical disintegration [42]. Among the causes mentioned to justify unemployment after the TBI, only one (male) patient mentioned lack of motivation at D180 but not at D365. This suggests that the majority of our patients actually considered work as a value of one individual's life. Improvement in outcomes could result from the use of models taking into account or favouring the view points and preferences of patients with TBI [43]. The other justifications of unemployment at D180 were the persistence of medical symptoms $(n=13)$, the inability to cope with prior job $(n=5)$, the inability to cope with administrative procedures $(n=5)$ and the unavailability of job arrangements $(n=2)$. Medical causes of unemployment were more common in the "Severe" $(n=11)$ than in the "Moderate" group $(\mathrm{n}=2)$. Most of the patients from the "Severe" group were suffering from chronic vegetative state or minimally conscious state without efficient improvement after their "Severe" initial TBI. Inability to cope with administrative procedures was more frequent in the "Moderate" $(\mathrm{n}=4)$ than in the "Severe" group $(\mathrm{n}=1)$.

At D365, the reasons justifying unemployment were medical disorders $(n=10)$, unavailability of job arrangements $(n=5)$, inability to cope with prior job $(n=1)$, and inability to cope with administrative procedures $(n=1)$. Medical causes of unemployment were more frequent in the "Severe" $(n=9)$ than in the "Moderate" group $(n=1)$, but unavailability of job arrangements was rather equally distributed in the "Severe" $(n=3)$ and in the "Moderate" group $(n=2)$. Although prevalence of subjective and behavioural complaints is high whatever the initial head trauma severity [44], the medical complaints in our series were still numerous in the "Severe group" from D180. Besides the medical disorders resulting from the brain injury, inability to cope 
with administrative procedures and unavailability of job arrangements were leading causes of poor employment outcomes from the $6^{\text {th }}$ month after the brain injury in our series. Indeed, better medical support could improve the patients' clinical states according to their own welfare standards. The medical management of TBIs could provide efficient multidisciplinary approach to optimize outcome inorder to foster vocational rehabilitation as supportive employment matching job demands to the worker's abilities $[13,45]$. Better understanding of the different parts of the work outcome profile of patients with TBI may also benefit the management of these cases [46]. Administrative procedures area complex matter that commonly requires intact executive functions and cognitive skills in healthy people. In our series, most of the patients presented disorders of attention, memory and executive functions at D180 and D365. Major depressive state, psychomotor agitation, character disorder and personality change are usually incompatible with complex processes which necessitate initiation, planning, organization, problem solving, verbal reasoning, mental flexibility, task switching and adequate monitoring of actions. Thus, our findings tend to reinforce the notion that the operating models and organizational structures commonly adopted by well-being individuals when solving complex issues are not consistent for most patients with TBI [ 47-50]. Recovery from cognitive deficits is greatest within the first 6 months after the TBI but further recovery can occur later on a more gradual mode [51]. Improvement may result from a multidisciplinary approach involving neuropsychologists to early evaluate and manage cognitive deficits along with mental health professionals such as psychiatrists and clinical psychologists. Cognitive and behavioural disturbances may also have a substantial impact on the functioning of the family systems as a result of many causes. Frustration to have lost a suitable pre-injury status, inability to cope with problems, difficulty in setting reachable goals, poor quality of communication and/or of reciprocal understanding have been mentioned [52-54]. In our study, communication problems were taken into account and appropriately treated (55); both the patients and their families had access to sustained psychological support. Psychoeducation and counseling models have been demonstrated to be effective in minimizing family disruption $[52,56]$. Nevertheless, the low success of professional reintegration programs suggests that further effort is required to further improve employment outcomes.

\section{Conclusion}

TBI encompasses its impact on society and rehabilitative management. Occupational reintegration takes time and requires a total apprehension of the problems which must be treated in all their clinical, psychological and social dimensions.

Although the sample of our study is very small, our results indicate that in all the patients who returned to work after their insult, professional reintegration was achieved along with both familial and social integration processes. Among positive features, young age at the time of the onset and facilities of arrangement of the work conditions tended to be useful. Early efficient multidisciplinary approach could early improve the patients' neuropsychological performances with positive impact upon the employment outcomes. Socioeconomic status appears to affect the possibilities of work recovery as patients with lower levels of education and employment showed poor outcome in returning to work. Severity of the initial injury to the brain, poor level of education and social isolation have shown lower functional outcome with lesser employment rates. Job arrangements are crucial at D365 for the patients who were severely injured and who were jobless or socially isolated on admission. Due to frequent cognitive and executive disorders, the common professional reintegration models are not consistent for most of the patients suffering from TBI. Larger improvement can be expected with oriented neurorehabilitation programs that nurture vocational rehabilitation as supportive employment matching job demands to the worker's abilities. After a TBI, both the patients and their families need psychological support, psychoeducation or counseling models in order to minimize distress and disruption. Complex problems management is frequent after a TBI and may require an external professional counseling or aid. Our results have to be confirmed at larger scale. However, due to the low success of the professional reintegration process, we conclude that further research is needed to improve the employment outcomes in patients after a TBI.

\section{Acknowledgment}

We thank Professor Mario Manto for the editing of the manuscript.

\section{References}

1. Marshall LF (2000) Head injury: recent past, present, and future. Neurosurgery 47: 546-561.

2. Crooks CY, Zumsteg JM, Bell KR (2007) Traumatic brain injury: a review of practice management and recent advances. Phys Med Rehabil Clin N Am 18: 681-710, vi.

3. Tagliaferri F, Compagnone C, Korsic M, Servadei F, Kraus J (2006) A systematic review of brain injury epidemiology in Europe. ActaNeurochir (Wien) 148: 255268

4. Yates PJ, Williams WH, Harris A, Round A, Jenkins R (2006) An epidemiological study of head injuries in a UK population attending an emergency department. J NeurolNeurosurg Psychiatry 77: 699-701.

5. Rooper AH, Gorson KC (2007) Concussion. N Engl J Med, 356:166-172.

6. Brown AW, Elovic EP, Kothari S, Flanagan SR, Kwasnica C (2008) Congenital and acquired brain injury. 1. Epidemiology, pathophysiology, prognostication innovative treatments, and prevention. Arch Phys Med Rehab 89 (3 Supplement 1): S3-8.

7. Kraus J, Sorenson S (1994) Epidemiology. In: Neuropsychiatry of Traumatic Brain Injury, Silver J, Yudofsky S, Hales R (Eds), American Press, Washington, DC.

8. Roberts I, Smith R, Evans S (2007) Doubts over head injury studies. BMJ 334 392-394.

9. DeKosky ST, Ikonomovic MD, Gandy S (2010) Traumatic brain injury--football warfare, and long-term effects. N Engl J Med 363: 1293-1296.

10. McCrea M, Guskiewicz K, Randolph C, Barr WB, Hammeke TA, et al. (2013) Incidence, clinical course, and predictors of prolonged recovery time following sport-related concussion in high school and college athletes. J Int Neuropsychol Soc 19: 22-33

11. Ghajar J (2000) Traumatic brain injury. Lancet 356: 923-929.

12. Posner JB, Clifford BS, Schiff N, Plum F (2007) Plum and Posner's Diagnosis of Stupor and Coma (4th ed.) Oxford University Press New York, NY.

13. Maas Al, Stocchetti N, Bullock R (2008) Moderate and severe traumatic brain injury in adults. Lancet Neurol 7: 728-741.

14. Cancelliere C, Kristman VL, Cassidy JD, Hincapié CA, Côté P, et al (2014) Systematic review of return to work after mild traumatic brain injury: results of the International Collaboration on Mild Traumatic Brain Injury Prognosis. Arch Phys Med Rehabil, 95:S201-9.

15. Filippelli G, Morrison D, Cicchella D (2012) Urban geochemistry and human health. Éléments, 8: 439-444.

16. Balestreri M, Czosnyka M, Chatfield DA, Steiner LA, Schmidt EA, et al. (2004) Predictive value of Glasgow Coma Scale after brain trauma: change in trend over the past ten years. J NeurolNeurosurg Psychiatry 75: 161-162.

17. Parikh S, Koch M, Narayan RK (2007) Traumatic brain injury. IntAnesthesiolClin 45: 119-135.

18. Saatman KE, Duhaime AC, Bullock R, Maas Al, Valadka A, et al. (2008) Classification of traumatic brain injury for targeted therapies. J Neurotrauma 25: 719-738. 
Citation: Catano A, Robert P, Houa M, Hutanu D, Bissen L, et al. (2015) Occupational Reintegration in Patients with Traumatic Brain Injury. Int J Neurorehabilitation 2: 150. doi:10.4172/2376-0281.1000150

19. Valadka AB (2004) Injury to the cranium. In: Trauma, Moore EJ, Feliciano DV Mattox KL New York: McGraw-Hill, Medical Pub Division, New york.

20. INSEE. Nomenclatures des Professions et Catégories Socioprofessionnelles (PCS 2003) 3ème éd, Paris, INSEE.

21. Mahoney F, Barthel DW (1965) Functional Evaluation: The Barthel Index. Md state med j 14: 61-65.

22. Collin C, Wade DT, Davies S, Horne V (1988) The Barthel ADL Index: a reliability study. IntDisabil Stud 10: 61-63.

23. Khaoulani N, Calmels $P$ (1991). Evaluation fonctionnelle par l'indice de Barthel. Ann Med PhysRéadapt 34 :129-136.

24. Dolce G, Sazbon L (2002) The post-traumatic vegetative state. Thieme Medical Publishers Inc.

25. Giacino JT, Kalmar K (1997) The Vegetative and Minimally Conscious States: A comparison of Clinical Features and Functional Outcome. J Head Trauma Rehabil 12: 36-51.

26. Kraus JF, McArthur DL (1996) Epidemiologic aspects of brain injury. Neurol Clin 14: 435-450

27. Rao V, Lyketsos C (2000) Neuropsychiatric sequelae of traumatic brain injury. Psychosomatics 41: 95-103.

28. Takahashi YK, Roesch MR, Stalnaker TA, Haney RZ, Calu DJ, et al. (2009) The orbitofrontal cortex and ventral tegmental area are necessary for learning from unexpected outcomes. Neuron 62: 269-280.

29. Damasio AR (1993) The frontal lobes. In: Neuropsychology, Heilman KM Valenstein E, (eds) Clinical 3rd ed. New York: Oxford University Press. pp. 409460

30. Hannay HJ, Howieson DB, Loring DW, Fischer JS, Lezak MD (2004). Neuropathology for neuropsychologists. In: Neuropsychological Assessment, Lezak MD, Howieson DB, Loring DW Oxford [Oxfordshire]: Oxford University Press.

31. Kim E, Lauterbach EC, Reeve A, Arciniegas DB, Coburn KL, et al. (2007) Neuropsychiatric complications of traumatic brain injury: a critical review of the literature (a report by the ANPA Committee on Research). J Neuropsychiatry Clin Neurosci 19: 106-127.

32. Jiang JY, Gao GY, Li WP, Yu MK, Zhu C (2002) Early indicators of prognosis in 846 cases of severe traumatic brain injury. J Neurotrauma 19: 869-874.

33. Hukkelhoven CW, Steyerberg EW, Rampen AJ, Farace E, Habbema JD, et al. (2003) Patient age and outcome following severe traumatic brain injury: an analysis of 5600 patients. J Neurosurg 99: 666-673.

34. Alban RF, Berry C, Ley E, Mirocha J, Margulies DR, et al. (2010) Does health care insurance affect outcomes after traumatic brain injury? Analysis of the National Trauma Databank. Am Surg 76: 1108-1111.

35. Heffernan DS, Vera RM, Monaghan SF, Thakkar RK, Kozloff MS, et al. (2011) Impact of socioethnic factors on outcomes following traumatic brain injury. $\mathrm{J}$ Trauma 70: 527-534

36. Halliday AL (1999) Pathophysiology. In: Traumatic Brain Injury Marion DW (ed) New York, NY: Thieme Medical Pubs.

37. Niedzwecki CM, Marwitz JH, Ketchum JM, Cifu DX, Dillard CM, et al. (2008) Traumatic brain injury: a comparison of inpatient functional outcomes between children and adults. J Head Trauma Rehabil 23: 209-219.

38. Thornhill S, Teasdale GM, Murray GD, McEwen J, Roy CW, et al. (2000) Disability in young people and adults one year after head injury: prospective cohort study. BMJ 320: 1631-1635.

39. Inzaghi MG, De Tanti A, Sozzi M (2005) The effects of traumatic brain injury on patients and their families. A follow-up study. EuraMedicophys 41: 265-273.

40. Kelli WG, Wilson B K (2012) Traumatic Brain Injury: Short, Long, and Very LongTerm Vocational Outcomes, Brain Injury - Functional Aspects, Rehabilitation and Prevention. Prof. AmitAgrawal (Ed.), ISBN:978-953-51-0121-5, InTech.
41. Kissinger DB (2008) Traumatic brain injury and employment outcomes: integration of the working alliance model. Work 31: 309-317.

42. Umberson D, Montez JK (2010) Social relationships and health: a flashpoint for health policy. J Health Soc Behav 51 Suppl: S54-66.

43. Sander AM, Clark A, Pappadis MR (2010) What is community integration anyway?: defining meaning following traumatic brain injury. J Head Trauma Rehabil 25: 121-127.

44. Masson F, Vecsey J, Salmi LR, Dartigues JF, Erny P, et al. (1997) Disability and handicap 5 years after a head injury: a population-based study. J Clin Epidemio 50: $595-601$

45. McMillan TM Oddy M (2000) Service provision for social disability and handicap after acquired brain injury. In: Neurobehavioural Disability and Socia Handicap Following Traumatic Brain Injury, Wood RL, McMillan TM (eds) East Sussex: Psychology Press.

46. Wehman P, Targett P, West M, Kregel J (2005) Productive work and employment for persons with traumatic brain injury: what have we learned after 20 years? J Head Trauma Rehabil 20: 115-127.

47. Draper K, Ponsford J (2009) Long-term outcome following traumatic brain injury: A comparison of subjective reports by those injured and their relatives. Neuropsychological Rehabilitation 19: 645-661.

48. Hesdorffer DC, Rauch SL, Tamminga CA (2009) Long-term psychiatric outcomes following traumatic brain injury: a review of the literature. $\mathrm{J}$ Head Trauma Rehabil 24: 452-459.

49. Hoofien D, Gilboa A, Vakil E, Donovick PJ (2001) Traumatic brain injury (TBI) 10 20 years later: a comprehensive outcome study of psychiatric symptomatology cognitive abilities and psychosocial functioning. Brain Inj 15:189-209.

50. Temkin NR, Corrigan JD, Dikmen SS, Machamer J (2009) Social functioning after traumatic brain injury. J Head Trauma Rehabil 24: 460-467.

51. Office of Communications and Public Liaison. (February 2002). Traumatic brain injury: Hope through research. NIH Publication No. 02-2478. National Institute of Neurological Disorders and Stroke, National Institutes of Health.

52. Kreutzer JS, Kolakowsky-Hayner SA, Demm SR, Meade MA (2002) A structured approach to family intervention after brain injury. J Head Trauma Rehabil 17: 349-367

53. Kreutzer JS, Stejskal TM, Ketchum JM, Marwitz JH, Taylor LA, et al. (2009) A preliminary investigation of the brain injury family intervention: impact on family members. Brain Inj 23: 535-547.

54. Lefebvre H, Cloutier G, JoséeLevert M (2008) Perspectives of survivors of traumatic brain injury and their caregivers on long-term social integration. Brain Inj 22: 535-543.

55. Mercat B, Renouf A, Kozlowski O, Rousseaux M (2006) [Management of communication in patients after severe traumatic brain injury. Pilot study]. Ann Readapt Med Phys 49: 150-154.

56. Parker R M, Szymanski E M, Patterson J B (2005) Rehabilitation counseling: Basics and beyond. Austin, TX: Pro-Ed. 